\title{
Black Anal Canal: Acute Necrosis
}

\author{
Sandra Barbeiro, Catarina Martins, Cláudia Gonçalves, Paulo Alves ${ }^{1}$, Inês Gil ${ }^{1}$, Manuela Canhoto, \\ Filipe Silva, Isabel Cotrim, Cristina Amado², Liliana Eliseu, Helena Vasconcelos \\ Departments of Gastroenterology, ${ }^{1}$ Surgery, and ${ }^{2}$ Pathology, Centro Hospitalar de Leiria, Leiria, Portugal
}

Acute ischemia of the rectum or anal canal resulting in necrosis is extremely uncommon because both the rectum and the anal canal have excellent blood supplies. We present a case with spontaneous necrosis of the anal canal without rectal involvement. Surgical debridement was accomplished, and the recovery was uneventful. The patient was elderly, with probable atherosclerotic arterial disease, and presented with hypotension. Due to the lack of other precipitating factors, the hypoperfusion hypothesis seems to be the most suitable in this case. To the best of our knowledge, no similar cases have been reported in the literature on this subject.

\section{Keywords: Anal canal; Ischemia; Necrosis; Black anal canal}

\section{INTRODUCTION}

Both rectal and anal involvement in ischemic disease is extremely rare due to the existence of an extensive collateral blood network in this anatomic region [1-3]. The authors describe a case of acute anal necrosis with neither rectal nor soft tissue affection.

\section{CASE REPORT}

An 83-year-old male presented to the Emergency Department with a 2-day history of diarrhea without blood. Past medical history included Alzheimer disease, arterial hypertension and diabetes mellitus (well controlled with insulin, but with known microvascular complications - retinopathy and nephropathy). Clinical information was provided by the caregivers because the patient was not communicative. They denied any history of trauma or topical medications. The patient was dehydrated and hypotensive. Abdominal exam was normal. Anal inspection revealed a dark-

Received: October 13, 2014 - Accepted: May 31, 2016

Correspondence to: Sandra Barbeiro, M.D.

Department of Gastrenterology, Centro Hospitalar Leiria, Rua das Olhalvas

2410-197 Leiria, Portugal

Tel: +351-244817000, Fax: +351-244817051

E-mail: sandrabarbeiro@gmail.com

(C) 2016 The Korean Society of Coloproctology

This is an open-access article distributed under the terms of the Creative Commons Attribution NonCommercial License (http://creativecommons.org/licenses/by-nc/4.0) which permits unrestricted non-

commercial use, distribution, and reproduction in any medium, provided the original work is properly cited. ened color of the anoderm (Fig. 1). Digital rectal examination was painful, with apparent hypotony of the anal sphincter, no palpable masses and no blood. Lymphadenopathy was absent.

Laboratory results revealed the following: leukocytes $(16,000 /$ $\mu \mathrm{L} ; 4,000-10,000 / \mu \mathrm{L}), \mathrm{C}$-reactive protein $(101.6 \mathrm{mg} / \mathrm{L} ;<5 \mathrm{mg} / \mathrm{L})$; creatinine kinase $(346 \mathrm{U} / \mathrm{L} ;<250 \mathrm{U} / \mathrm{L})$; lactate dehydrogenase (196 U/L; 50-115 U/L). Flexible sigmoidoscopy showed a circumferential darkening of the anal canal (total distance of 25 $\mathrm{mm}$ ), with a proximal margin $2 \mathrm{~mm}$ below the dentate line and a normal rectal mucosa with brown molded feces inside the rectum (Fig. 2). Histopathology showed a polymorphic inflammatory infiltrate, with extensive necrosis and ulceration up to the hypodermis (Fig. 3). Microbiology was negative. No imaging study, such as computed tomography, magnetic resonance, endoanal ultrasound, or angiography, was performed due to the patient's performance status. Anal sphincter function was not evaluated because the patient was not cooperative.

After admission, diarrhea was no longer observed. Hypotension quickly improved after fluid therapy with normalization in the first 2 hours after admission. Anal lesions were not improved after 5 days of medical therapy (broad-spectrum parenteral antibiotics and intravenous fluids). On day 6 after admission, surgical debridement with superficial necrotic tissue removal and hemostasis with an absorbable haemostatic gelatin sponge was performed. During surgery, gangrenous superficial tissues were noticed, but muscular tissue and the anal sphincter were spared. The patient's perianal findings were clearly improved 5 days after surgical treatment (Fig. 4). After 10 months of follow-up, neither cutaneous le- 

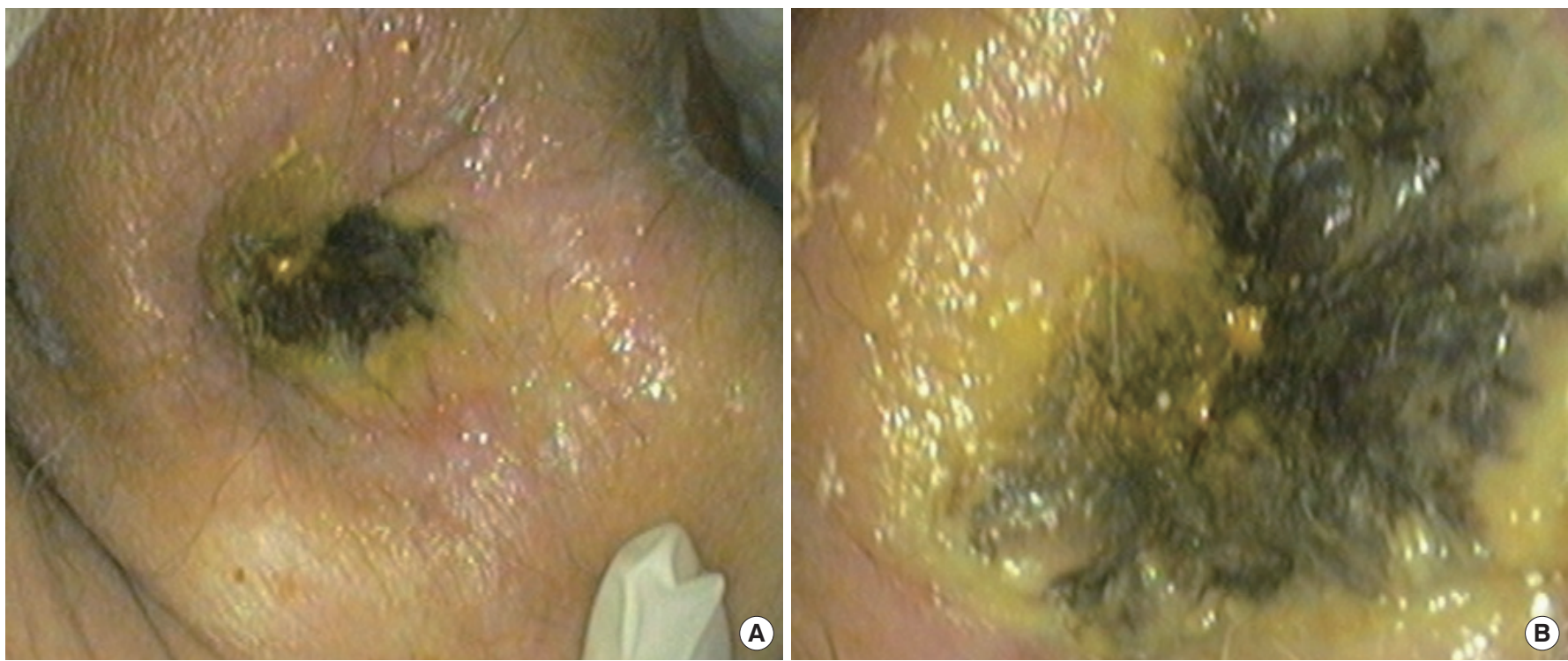

Fig. 1. (A) Anal inspection showed a darkened color of the anoderm. (B) Magnified view of the area shown in panel A.
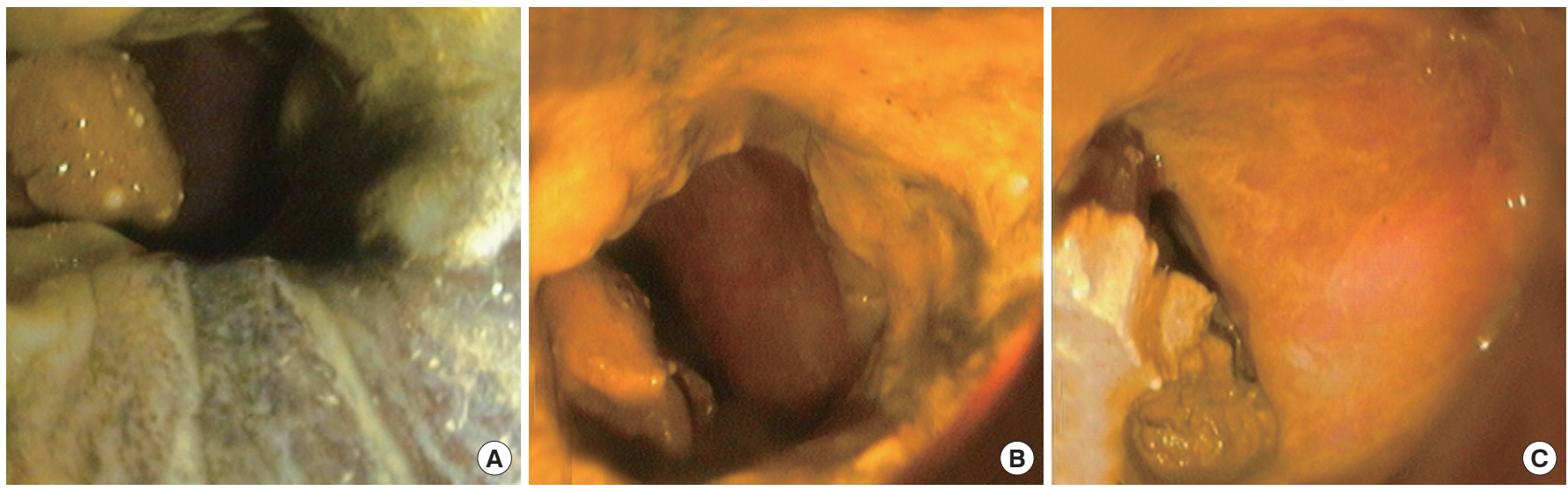

Fig. 2. Flexible sigmoidoscopy showed circumferential darkening of the anal canal (A) and the normal rectal mucosa (B, C).

sions nor fecal incontinence had occurred.

\section{DISCUSSION}

Ischemia of the anal region is rare because this region has a very rich vascularization [1-4]. The anal canal is supplied by the inferior, middle and superior rectal arteries, which communicate between themselves and with branches of the lumbar, internal iliac and inferior vesical arteries [1-4]. The hemorrhoidal plexus drains the superior rectal (portal circulation) and the middle and inferior rectal veins (systemic circulation), establishing an important portosystemic anastomotic network $[1,3,4]$. An extensive search in the literature revealed a single case of anal sphincter necrosis as a result of an electric current injury [5], 2 cases of anorectal necrosis secondary to hemorrhoidal sclerotherapy $[6,7]$ and 2 cases of anorectal necrosis after paracetamol suppository abuse [8, 9].

Cases of rectal and anal ischemia almost invariably include risk factors such as advanced age, atherosclerotic disease, arterial hypertension or diabetes mellitus $[1,2,10]$. Other causes of rectal ischemia include embolization during angiography, hemorrhoid infection, vasculitis, systemic lupus, radiotherapy, and phosphate enema application [1, 11-15]. Sometimes, no precipitating event can be identified [1]. In our case, the hypoperfusion hypothesis seems to be the most plausible explanation because the patient had arterial hypotension and microvascular complications of diabetes mellitus. In addition, the patient's malnutrition and frailty compromised the barrier and healing mechanisms. Despite the absence of any reference, the possibility of chemical or traumatic injury cannot be excluded. Diarrhea was attributed to transient anal incontinence upon ischemia. This hypothesis is further sup- 


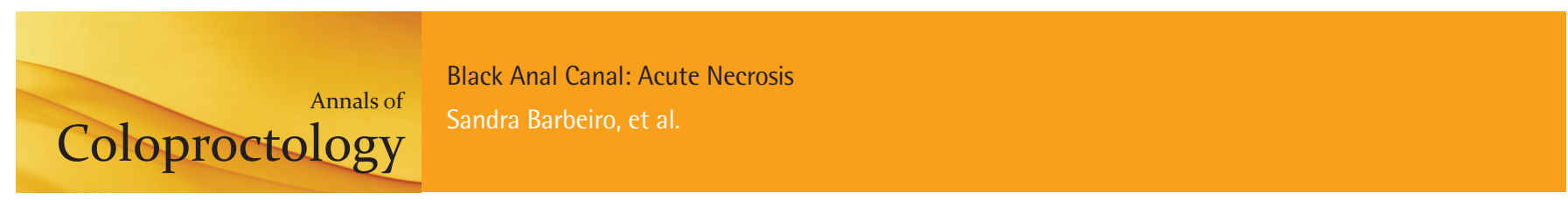

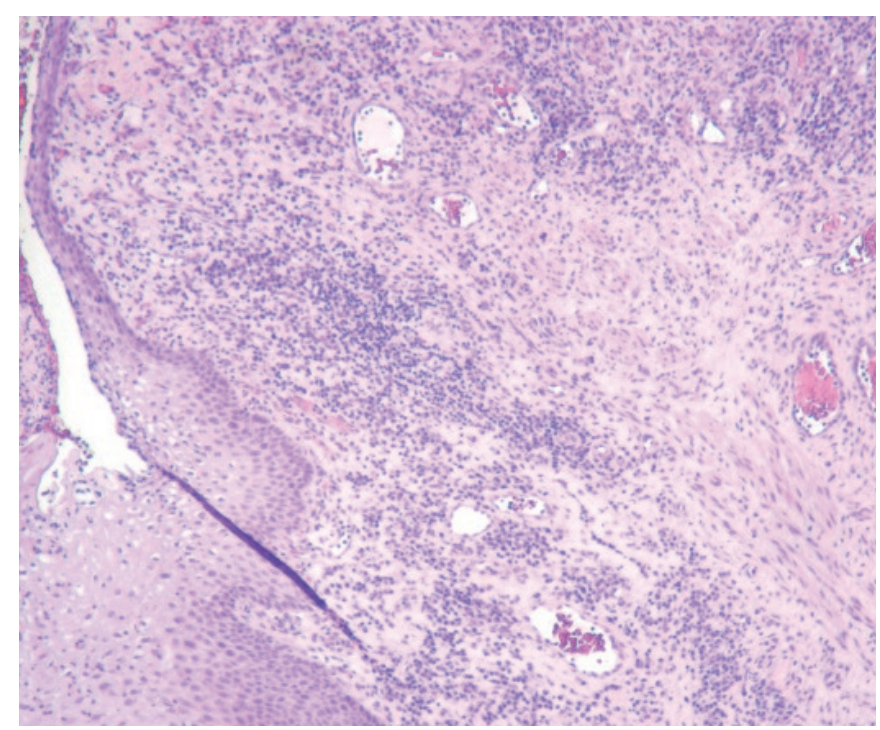

Fig. 3. Histopathology showed a polymorphic inflammatory infiltrate with extensive necrosis and ulceration, but without vascular thrombi or neoplastic cells $(\mathrm{H} \& \mathrm{E}, \times 100)$.

ported by the absence of diarrhea after admission and by the presence of solid feces in the lumen during the flexible sigmoidoscopy. The patient's recovery after surgical treatment was favorable, as a clear improvement in the lesions was noted.

Spontaneous anal necrosis is an apparently unknown clinical entity, with no similar cases having been discussed in the literature until now. This case underlines the importance of a detailed physical examination to reach the correct diagnosis.

\section{CONFLICT OF INTEREST}

No potential conflict of interest relevant to this article was reported.

\section{REFERENCES}

1. Azimuddin K, Raphaeli T. Acute ischemic gangrene of the rectum: report of 3 cases and review of literature. Int J Surg Case Rep 2013;4:1120-3.

2. Maun D, Silverberg D, Steinhagen RM. Acute ischemic proctitis: report of four cases. Dis Colon Rectum 2007;50:1082-6.

3. Gray H, Lewis WH. Anatomy of the human body. 20th ed. New York: Bartleby; 2000.

4. Kornblith PL, Boley SJ, Whitehouse BS. Anatomy of the splanchnic circulation. Surg Clin North Am 1992;72:1-30.

5. Yildirgan MI, Basoglu M, Balik AA, Aydinli B. Anal canal ampu-

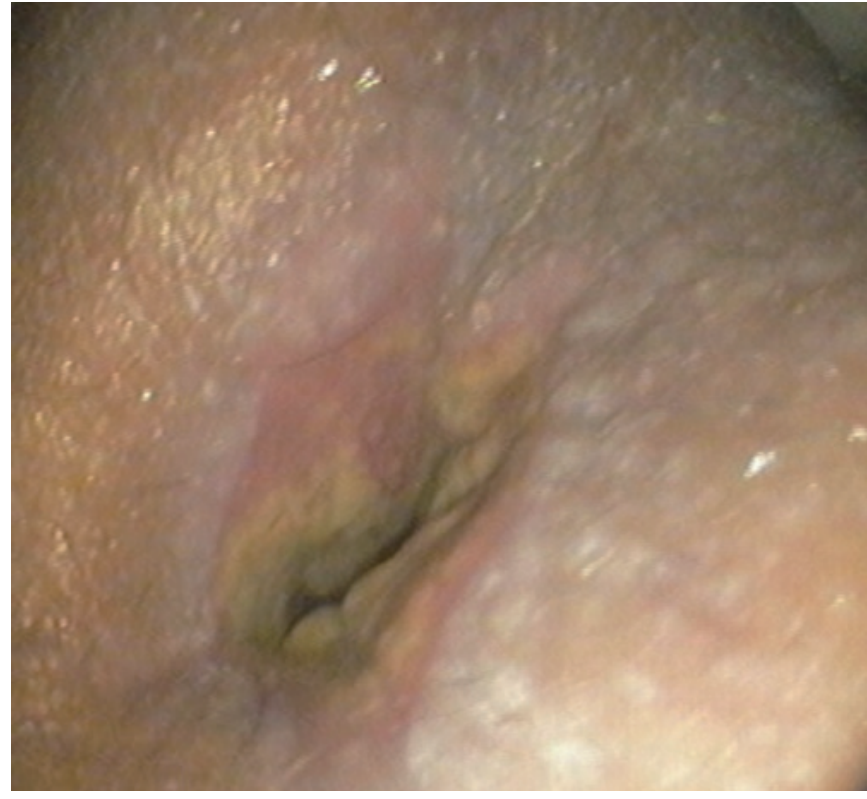

Fig. 4. Perianal findings on day 5 after surgical debridement.

tation and necrosis of the anal sphinchter due to electric current injury. Int J Clin Pract 2002;56:405-6.

6. Elram R, Wasserberg N. Anorectal necrosis induced by injection sclerotherapy for hemorrhoids. Int J Colorectal Dis 2007;22:997-8.

7. Schulte T, Fandrich F, Kahlke V. Life-threatening rectal necrosis after injection sclerotherapy for haemorrhoids. Int J Colorectal Dis 2008;23:725-6.

8. Streit E, Gholam P, Hadaschik E, Hartschuh W. Anorectal necrosis after paracetamol abuse. Br J Dermatol 2014;170:217-8.

9. Schmutz JL, Trechot P. Anorectal necrosis and paracetamol suppository abuse. Ann Dermatol Venereol 2014;141:402-3.

10. Nelson RL, Briley S, Schuler JJ, Abcarian H. Acute ischemic proctitis: report of six cases. Dis Colon Rectum 1992;35:375-80.

11. Sweeney JL, Hewett P, Riddell P, Hoffmann DC. Rectal gangrene: a complication of phosphate enema. Med J Aust 1986;144:374-5.

12. Smith I, Carr N, Corrado OJ, Young A. Rectal necrosis after a phosphate enema. Age Ageing 1987;16:328-30.

13. Sashida Y, Kayo M, Matsuura K, Kuwabara K, Samura H, Dakeshita E. Rectal gangrene: a rare complication of infected hemorrhoid. Jpn Assoc Acute Med 2000;11:285-8.

14. Reissman P, Weiss EG, Teoh TA, Lucas FV, Wexner SD. Gangrenous ischemic colitis of the rectum: a rare complication of systemic lupus erythematosus. Am J Gastroenterol 1994;89:2234-6.

15. Kotze PG, Martins JF, Sella GV, Rocha JG, Miranda EF. Perineal necrosis following radiotherapy for prostate cancer: case report. Rev Bras Coloproct 2007;27:452-5. 